\title{
THICKENING OF ALUM SLUDGE USIN FLOATABLE MEDIA FILTER
}

El-Gendy, A. Sh. ${ }^{(1)}$; Abd El-Razek, T. A. M. ${ }^{(1)}$ and Abd El-Monem, Sh. 1) Institute of Environmental Studies and Researches, Ain Shams University

\begin{abstract}
A pilot scale filter was tested for thickening of alum sludge generated during the production of potable water in a conventional compact water treatment plant (WTP). The alum sludge is produced from coagulation / flocculation / sedimentation processes that are using aluminum sulfate (Alum) (A12 (SO4)3. 18H2O). The pilot scale was fabricated from scheduled uPVC pipe. The reactor was filled with floatable media (polystyrene) working as filtration media with counter flow concept. The alum sludge was discharged in the pilot scale setup from the sludge holding tank in the WTP using submersible pump.

The pilot scale filter was tested at different rate of filtration (ROF) ranged from 25 to $400 \mathrm{~m} 3 / \mathrm{m} 2 / \mathrm{d}$. In addition, different media heights $(100-$ $800 \mathrm{~mm}$ ) were investigated to study the efficiency of the sludge thickening. The filter washing rate (ROW) was tested to determine the optimum ROW that will clean the filter. ROW equal to one to four times the ROF were investigated. The efficiency of the sludge thickening was achieved around $30 \%$ at the optimum range of ROF that founded in the range of $150-200$ $\mathrm{m} 3 / \mathrm{m} 2 / \mathrm{d}$ and the filtration media height between $400-600 \mathrm{~mm}$. at the optimum operating conditions, the floatable media filter had the ability to thicken the alum sludge and, the turbidity of the water produced after thickening were less than 12 NTU.
\end{abstract}

Key words: Thickening of alum sludge - Dewatering of alum sludge

\section{INTRODUCTION}

Conventional water treatment plants consist of several treatment processes. These processes include coagulation / flocculation, sedimentation, filtration and disinfection (Jekel., 1989). The coagulation of waters using 
aluminum sulphate often leads to the formation of sludges which are gelatinous in character and usually require conditioning prior to dewatering. (Bache,and. Papavasilopoulos, 2003). The coagulation-flocculation process usually generates large quantities of chemical sludge, especially the alum, which must be properly managed. (Jangkorn etal, 2011). Coagulation process involves the addition of coagulants such as aluminum sulfate (Alum) [(AL2 (SO4)3. 18H2O)] which is always used in Egypt. The alum is usually added in a dose range of $25-40 \mathrm{mg} / \mathrm{l}$ (El-Nahhas, 2011). The added coagulant (Alum) reacts with water Alkalinity and produces a gelatinous precipitate (Flocs) grow by slow mixing of water (flocculation) and then settle in the sedimentation tank. These flocs remove most of colloidal and suspended particles from raw water during sedimentation (Bache, and Gregory, 2007). The settled flocs are collected at the bottom of the sedimentation tank. The collected flocs are called "Alum Sludge" (Bratby J. ,2006).

The management of alum sludge is a major problem which faces water treatment plant (WTP) operators. This is due to the difficulty of dewatering and disposal of this type of sludge (Kathy, 2005). The common engineering practice used for alum sludge dewatering includes sludge thickening by using lagoons or drying bed technologies. These technologies provide very low dewatering efficiency (maximum of 15\%) and require large footprint area (USEPA, 2002). Other practices for dewatering include filter press, belt filter press and centrifuge technologies. These technologies can provide moderate dewatering efficiencies which ranges from $30 \%-50 \%$. However, they require 
skilled labors and high running costs due to operation and maintenance (WHO, 2004).

In Egypt, alum sludge for water treatment plant (WTP) is usually disposed without treatment or dewatering downstream of the water treatment plant intake (El-Nahhas, 2011). This practice is unacceptable because of its negative impacts on the environment. However, in a limited number of water treatment plants (WTPs), drying beds is used for dewatering of alum sludge (Statistics Dept., Technical Service Sector, 2011).

In 2011, the average alum sludge produced from water treatment plants (WTPs) in Greater Cairo is $436,554 \mathrm{~m} 3 /$ day. The average concentration of solids in this sludge usually ranges between $3 \%$ and $5 \%$. (Statistics Dept., Technical Service Sector, 2011). On the other hand, the dewatering of this massive quantity of the alum sludge using drying beds or lagoons needs a very large footprint area and therefore, a high capital cost. Also, it will be even more costly to dewater this quantity using high technologies for dewatering such as belt press, filter press or centrifuge. This is in addition to the requirements of highly skilled labors and high running costs for these high technologies. Therefore, there is a need for an efficient system that can dewater the alum sludge produced from water treatment at a reasonable cost.

\section{MATERIAL \& METHODS}

Description of Abu-Dahshan WTP: The experiments were carried out in Abu-Dahshan drinking water treatment located in Ismailia city with capacity of 100 cubic meter per hour. This plant is one of many similar plants in different locations that called "compact units". The main problem in this type 
of plants is the disposal of the collected alum sludge as a result of water treatment into downstream the intake point of the water treatment plant. The raw water is feeding the plant from Ismailia canal at the ambient temperature. The characteristics of the raw water used in this study are listed in Table 1

Table(1): Raw water characteristics

\begin{tabular}{|c|c|}
\hline Parameters & Value \\
\hline \hline $\mathrm{pH}$ & 7.8 \\
\hline Turbidity & $18 \mathrm{NTU}$ \\
\hline Temp. & $22-26^{\circ} \mathrm{C}$ \\
\hline Total suspended solids (TSS) & $33 \mathrm{mg} / \mathrm{L}$ \\
\hline
\end{tabular}

The treatment processes in Abu-Dahshan WTP include coagulation / flocculation followed by sedimentation then filtration using rapid sand filter. The finished water is then disinfected using chlorine before pumping to the community. The alum collected at the bottom of the sedimentation tank along with water from filter washing are directed to a sludge holding tank before disposal in the downstream the intake which controlled by level of the alum sludge inside sludge holding tank. The collected alum sludge is feeding the pilot setup continuously as produced in the settlement process from the drinking water treatment plant by intermediate tank called "sludge holding tank" to ensure homogenous and continuous flow before pumped to the pilot scale. The experimental runs based on the following characteristics of the alum sludge. 
Table(2): Alum sludge characteristics

\begin{tabular}{|c|c|}
\hline Parameters & Value \\
\hline Temp & $26^{\circ} \mathrm{C}$ \\
\hline Turbidity & $297.7 \mathrm{NTU}$ \\
\hline Total suspended solids (TSS) & $686 \mathrm{mg} / \mathrm{l}$ \\
\hline
\end{tabular}

Description the Pilot-Scale Setup: The pilot-scale setup was fabricated from scheduled uPVC pipe, it has a diameter of $300 \mathrm{~mm}$ (12 inch) and $2000 \mathrm{~mm}$ length. The pipe is connected by couple of movable flanges with welded socket to access charging the insert media easily and for cleaning purpose. Both of upper and bottom sides are closed by blind flanges through stainless steel bolts connected with the movable flanges. Raw sludge inlet, filtered water outlet and thickened sludge outlet are controlled by isolating valves (size $1 \frac{1}{2}$ inch). The connecting pipes in the scale were made from uPVC also. Pressure gauges were installed at different points in the setup to monitor the pressure drop through the system. The filter was filled partially with uniform polystyrene media diameter $1 \mathrm{~mm}$ which has low density. Therefore, the media particles float upward in the filter with the flow of alum sludge. A set of PVC nozzles was installed on the top of the pilot to prevent escaping of the media during the normal operation. The filtered water was collected from the top of the filter in a tank with dimension of $480 \times 480 \times 600 \mathrm{~mm}(\mathrm{~L} \times \mathrm{W} \times$ D) which was fabricated from transparent acrylic sheets thickness $8 \mathrm{~mm}$. The collected thickened sludge was discharged through a flexible hose from the bottom of the filter (below the media). Figure (1), shows a schematic diagram of the pilot scale setup of the floatable media filter. As shown in the Figure (1). 


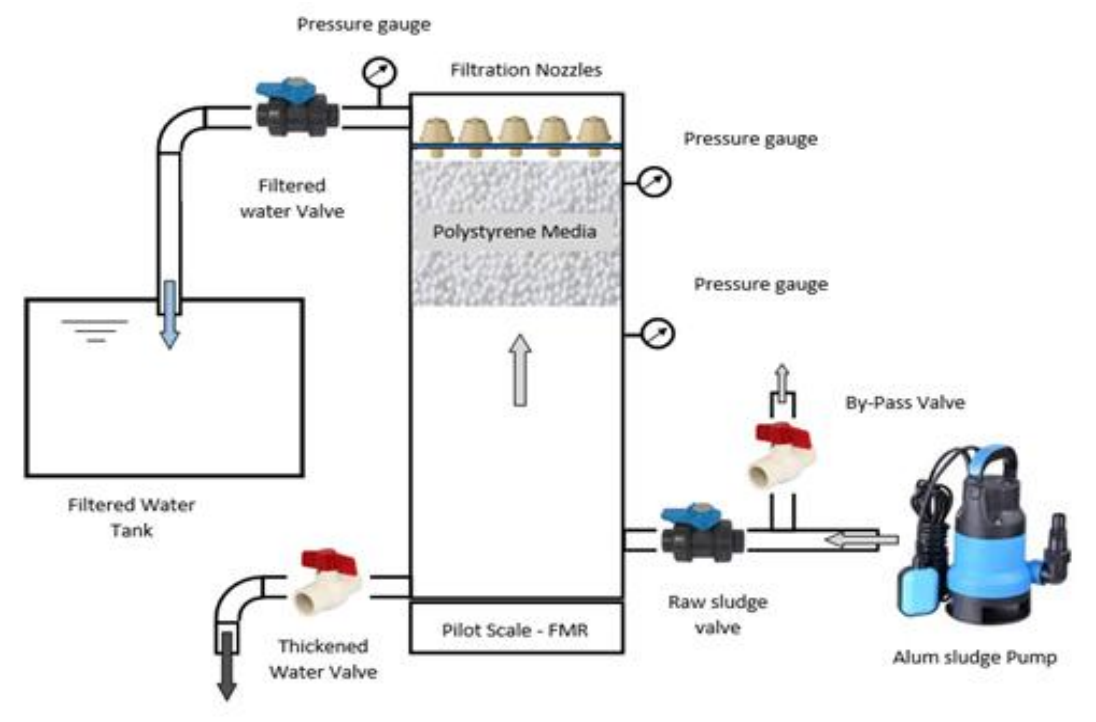

Figure(1): Schematic diagram for Floatable Media Filter (FMR)

Alum sludge is pumped to the setup from sludge holding tank at AbuDahshan WTP using a submersible pump. The pump capacity is $1 \mathrm{~m} 3 / \mathrm{hr}$ at 20 $\mathrm{m}$ head. The material construction for Body and impeller are cast iron GG25 the power supply $230 \mathrm{~V}$ AC and absorbed power $0.5 \mathrm{hp}$. The pump manufacturer Tsurumi - Japanese made otherwise this pump is recommended for our case study. After pumping, sludge flows through the media in the upward direction. At normal operation both raw sludge inlet valve and Filtered water outlet valve are opened at the end of the operating cycle, the thickened water valve is opened to collect the thickened sludge in case of closing both of inlet valve and outlet valve.

Experiment Setup: The experiment of the current work were carried out in two phases; phase I and phase II. In phase I, experiments were carried out to investigate the optimum operating parameters of the pilot scale setup in 70 
thickening the alum sludge. In phase II, a comparison between pilot setup and conventional thickener were investigated.

Phase I: In this phase, different operating parameters for the operation of the floatable media filter were investigated.

1. Rate of filtration (ROF): The selected ROFs 25, 50, 100, 150, 200 and $400 \mathrm{~m} 3 / \mathrm{m} 2 /$ day are covered all types of filtration process.

2. Media height : Different media heights has been tested as follows: 100, 200, 400, 500, 600 and $800 \mathrm{~mm}$ to cover wide range of pilot setup height.

3. Time of filter operation: The filter was operated at each condition till the pressure drop equals to 1 bar. At this point; the operation of the filter stopped the back washing of the filter started.

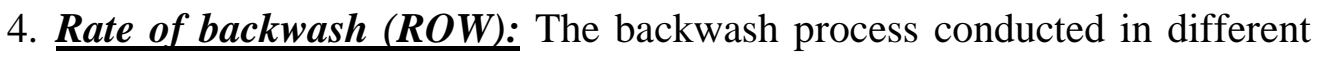
rates related to the rate of filtration such as ROF, $1.5 \mathrm{ROF}, 2 \mathrm{ROF}$, 2.5ROF, 3ROF and 4ROF. The backwash was carried out by pumping of filtered water into the system in the reverse direction of filtration. During backwashing the filter was out of operation and no filtered water is produced.

Phase 2: In this phase, the floatable media filter was operated at two different conditions; the first was the optimum operating condition obtained in phase 1 in terms of ROF. While the second condition include the operation at a ROF equal to the recommended surface overflow rate of the conventional thickener as given by the Egyptian code of practice (ECP 2016). 
On the other hand, conventional thickener was operated at the values (36 $\mathrm{m} 3 / \mathrm{m} 2 / \mathrm{d}$ ) recommended by ECP, and at a surface overflow equal to the optimum rate of filtration of the filter. This was to compare the performance of both technologies in thickening the alum sludge.

Description the Pilot-Scale Setup of the thickener: The pilot-scale setup of the thickener was fabricated from scheduled UPVC pipe, it has a diameter of $300 \mathrm{~mm}$ (12 inch) and $2000 \mathrm{~mm}$ length. Both of upper and bottom sides are closed by blind flanges through stainless steel bolts connected with the movable flanges. Raw sludge inlet, filtered water outlet and thickened sludge outlet are controlled by isolating valves (size $1 \frac{1}{2} 2$ inch). The connecting pipes in the scale were made from uPVC also. The filtered water was collected from the top of the filter in a tank with dimension of $480 \times 480 \times 600 \mathrm{~mm}$ $(\mathrm{L} \times \mathrm{W} \times \mathrm{D})$ which was fabricated from transparent acrylic sheets thickness 8 $\mathrm{mm}$. The collected thickened sludge was discharged through a flexible hose from the bottom of the filter.

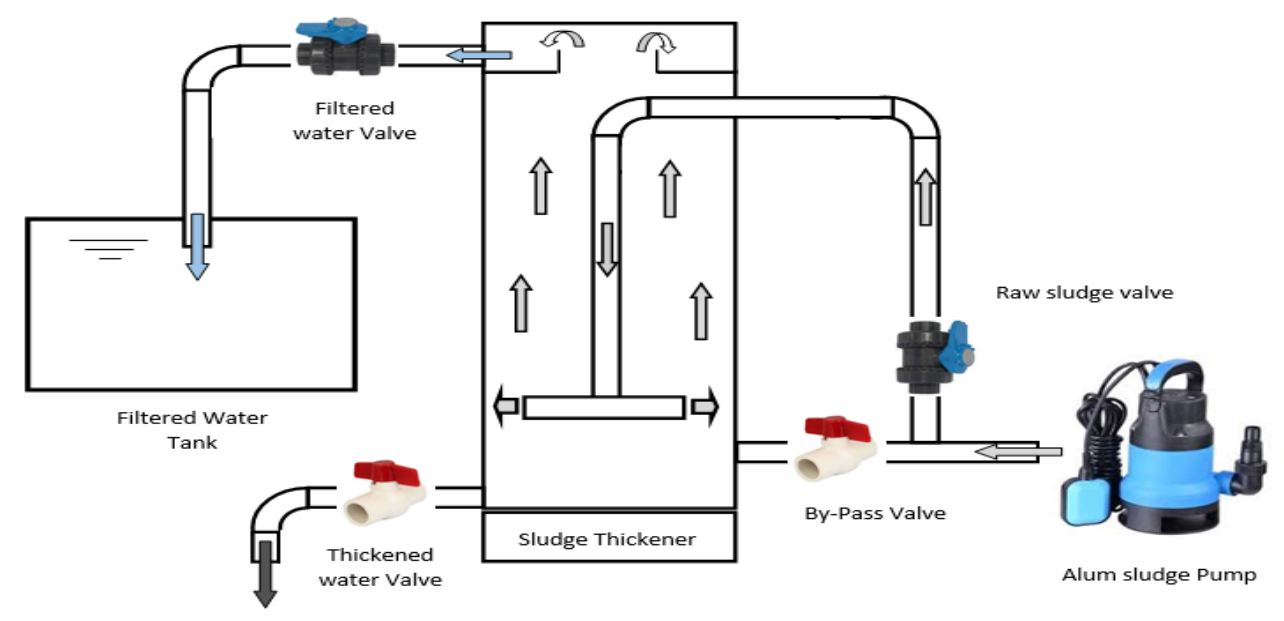

Figure(2): Schematic diagram for conventional thickener 72 
The pump capacity is $1 \mathrm{~m} 3 / \mathrm{hr}$ at $20 \mathrm{~m}$ head. The material construction for Body and impeller are cast iron GG25 the power supply $230 \mathrm{~V}$ AC and absorbed power $0.5 \mathrm{hp}$. The pump manufacturer Tsurumi - Japanese made otherwise this pump is recommended for our case study. At normal operation both raw sludge inlet valve and filtered water outlet valve are opened at the end of the operating cycle, the thickened water valve is opened to collect the thickened sludge in case of closing both of inlet valve and outlet valve. The pilot-scale setup illustrated in Figure (2).

\section{Sampling and sample analysis:}

Sampling: In order to evaluate the performance of the floatable media filter or conventional thickener in thickening alum sludge samples were collected from different position in the system and analyzed for specific parameters. The samples were collected from;

1. Influent of each system to represent raw alum sludge

2. The effluent supernatant or filtered water

3. The thickened sludge

In phase I, all collected samples were analyzed for TSS and turbidity. In phase II all collected samples were analyzed for TSS.

All analysis were carried out according to the standard methods for water and wastewater examination (APHA,2005).

\section{RESULTS \& DISCUSSION}

The pilot scale setup was tested several times along one year of experimental runs to obtain best performance of the system this helped in achieving the optimum values of the operating parameters. 
Effect of different rates of filtration (ROF) on filtered water quality at different height of media of the FMR.: Several values of the rate of filtration were tested to cover the wide range of ROF at different levels of media height. Figure (3) illustrate the effect of ROF on the quality of the filtered water.

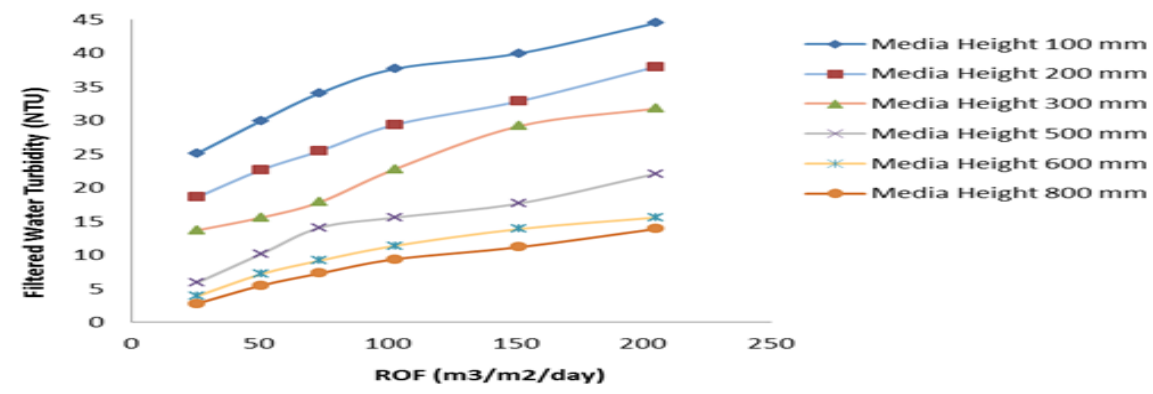

Figure (3): Effect of ROF on the quality of filtered water

As shown in Figure (3), as the ROF increased, the quality of the filtered water decreased due to the increase of the turbidity. In addition, it was observed also as the depth of the filtration decreased, the quality of the filtered water decreased

Effect of different values of ROF on operating cycle (working hours) at different height of media of the FMR

The operating cycle time refers to the duration in minutes of the normal operation of the FMR to reach pressure difference of 1 bar $(\Delta \mathrm{P}=1$ bar $)$ between the influent of the FMR and the filtered water effluent of the FMR 


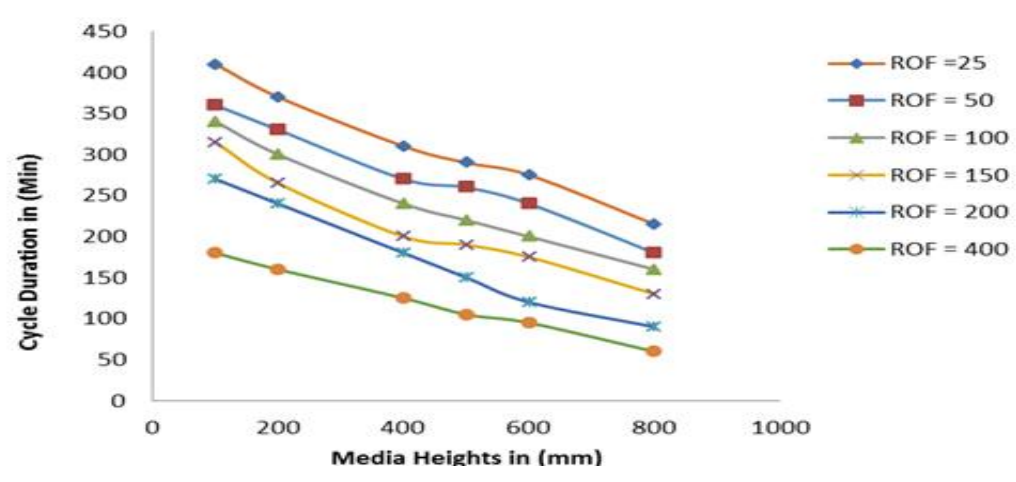

Figure(4): Effect of ROF on the duration of one cycle of operation at different media height

(One cycle of operation is a cycle duration which the pressure difference between the influent and the effluent of FMR does not exceed 1 bar)

Figure (4) shows the effect of ROF on the duration of one operating cycle of the FMR filter. As shown in Figure 4 as the ROF increases, the duration of one operating cycle decreases because the filter gets clogged. Also as the media height increased, the filter resistance increased compared to filter with less height. This means that the media height has negatively affected the duration of operation of one cycle of the filter, which means higher frequency of filter washing.

Relation between filtered water quality and time of the operation cycle: The filtered water quality changes with the time of the operating cycle due to the accumulated suspended solid on the surface of the filtration media which resist the flow and effect on the quality of the filtered water. 
Figure (5) illustrate the relation between filtered water quality and operation cycle time. From this relation we can get the optimum duration of operation cycle at each rate of filtration (ROF) according to the changes in filtered water quality.
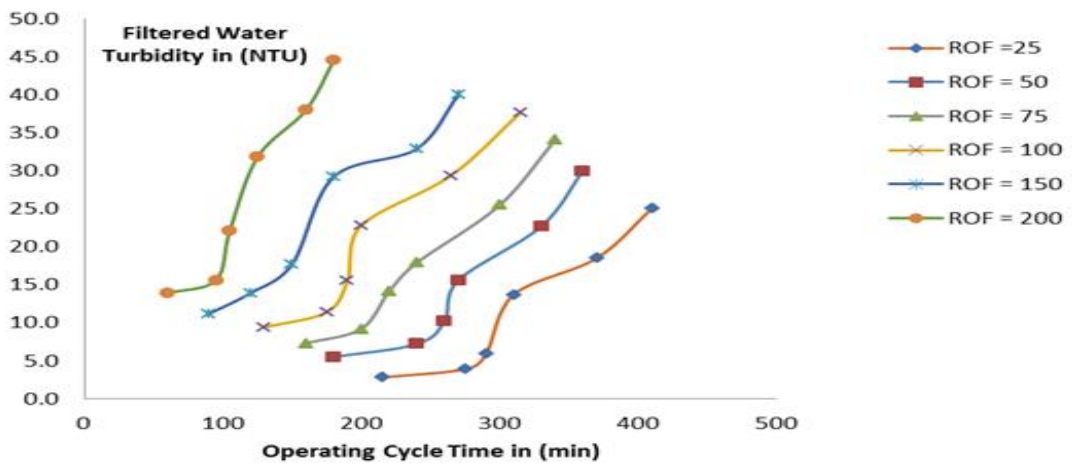

Figure (5): Effect of duration of operating cycle on the quality of the filtered water from the FMR

Effect of different rates of backwash on filter cleaning: Backwash process is an important factor for operating and testing any filtration system considering the rate of backwash and time needed to clean the filter. Actually this relation explains how the rate of flow and time of the backwash process affected the backwash efficiency. In similar filtration application the rate of backwash is equal to 3-5 times rate of filtration. The rate of filtration considered in this runs is $200 \mathrm{~m} 3 / \mathrm{m} 2 /$ day. And media height $500 \mathrm{~mm}$. As normal the direction of the backwash is against the direction of the normal operation, this mean the flow is downward from top to bottom. 


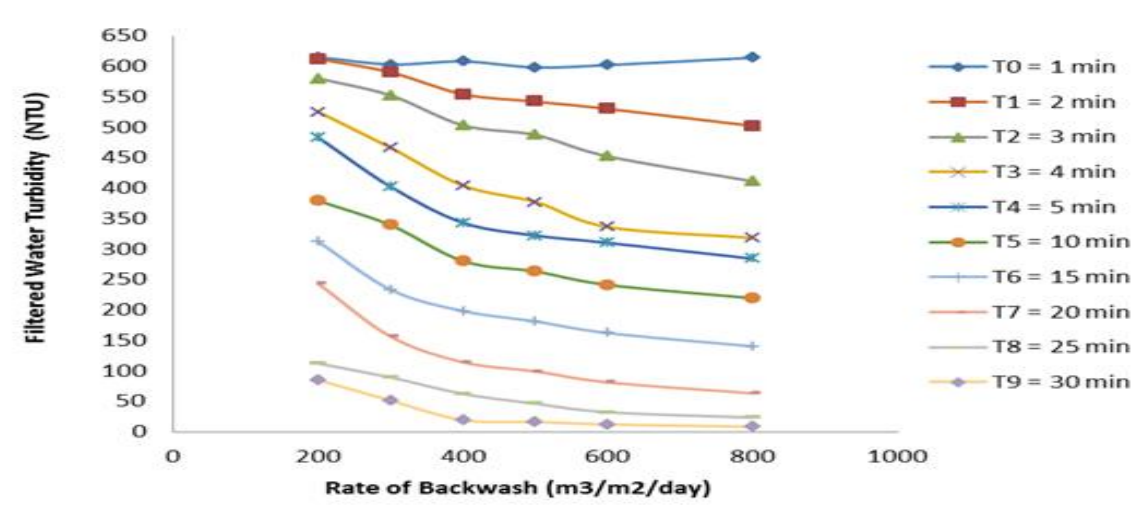

Figure (6): Effect of duration of operating cycle on the quality of the filtered water from the FMR

Figure (6) refer to the time of backwash and its flow rate against the filtered water turbidity as an indicator of cleaning whereas the filtered water used in cleaning has the same turbidity of the outlet of backwash valve this mean that the backwash process was efficient and in normal operation, the operating cycle time given the same quality and quantity of the filtered water.

\section{Optimum operating parameters for FMR}

1. Optimum Rate of Filtration (ROF) Referring to figure (3) the minimum filtered water quality 2.8 NTU was achieved at the highest level of media height $800 \mathrm{~mm}$ and minimum rate of filtration (ROF) $25 \mathrm{~m} 3 / \mathrm{m} 2 /$ day. Whereas the maximum filtered water quality 44.5 NTU was achieved at the lowest level of media height $100 \mathrm{~mm}$ and maximum rate of filtration (ROF) $200 \mathrm{~m} 3 / \mathrm{m} 2 /$ day. As achieved, while the rate of filtration decreased at constant height of media, the filtered water quality will be improved. As well as the height of media increased at constant rate of filtration, the filtered water quality improved also. The resistant to raw sludge flow through the media helps to eliminate the suspend solids to passed out as 
filtered water. So that the relation of height of media is proportional with the filtered water quality. And according to standard operating condition in the pressurized sand filter; the optimum rate of filtration in this study 200 $\mathrm{m} 3 / \mathrm{m} 2 /$ day also.

2. Optimum height of media: From the FMR the filtered water will be directed toward the influent of the water treatment plant. As the WTP influent (raw water) has a turbidity of 12 to $18 \mathrm{NTU}$, therefore, the quality of the filtered water should be at least similar to that of raw water. Therefore, as shown in Figures 3 and 4, the recommended media height should be at least $500 \mathrm{~mm}$ to ensure a matching quality of the filtered water to the raw water.

3. Operating cycle (working hour): Figure (5) explain the effect of operating condition on the operating cycle. Where the minimum operating cycle time 60 minutes was achieved at the highest level of media height $800 \mathrm{~mm}$ and maximum rate of filtration (ROF) $200 \mathrm{~m} 3 / \mathrm{m} 2 /$ day. Whereas the maximum operating cycle time 410 minutes was achieved at the lowest level of media height $100 \mathrm{~mm}$ and minimum rate of filtration (ROF) 25 $\mathrm{m} 3 / \mathrm{m} 2 /$ day. As achieved, while the rate of filtration decreased at constant height of media, the operating cycle time will be increased. While the height of media increased at constant rate of filtration, the operating cycle time will be decreased. The resistant to raw sludge flow through the media helps to eliminate the suspend solids to passed out so that the media shall be blocked accordingly. On the other hand, the time taken to pass the raw sludge through the media helps to precipitate the suspended solids on the 
surface of the media so that the media will be blocked also.. Therefore, operating cycle time at this operating conditions is 105 minutes.

Optimum Rate of backwash (ROW): As illustrated in the figure (6) when the rate of backwash increased at constant backwash time the cleaning process improved, so it can improved much better when the backwash time increased also. The minimum backwash time to achieve good cleaning is 25 minutes at rate of backwash equal four times rate of filtration. Or 30 minutes at rate of backwash equal three times rate of filtration

\section{Water sampling}

1. Pilot setup water sample: Figure (7) illustrate the different colors of water depending on its turbidity. As shown in the figure, the clear sample is for filtered water, the darker sample is for thickened sludge and the one in between refer to the alum sludge sample.

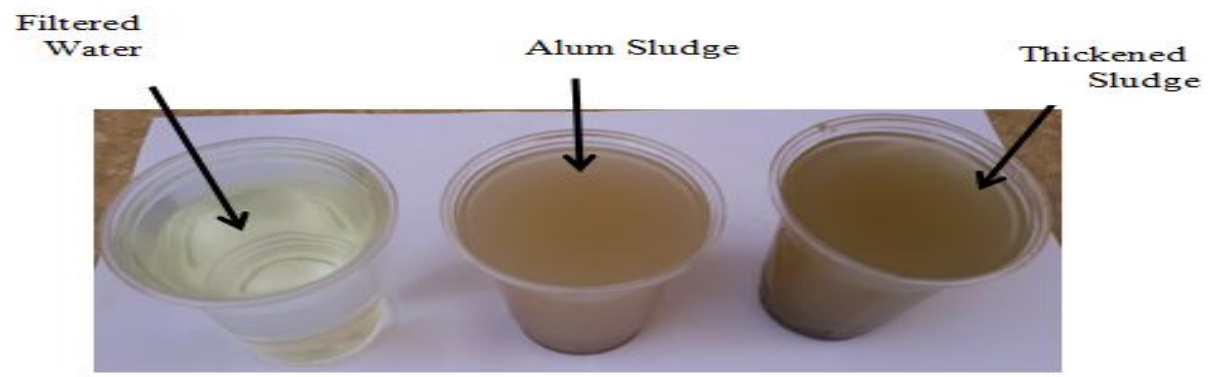

Figure(7): FMR sludge and water samples

2. Convectional clarified water sample: Figure (8) illustrate the different colors of water depending on its turbidity. As shown in the figure, the clear sample is for clarified water, the darker sample is for thickened sludge and the one in between refer to the alum sludge sample. 
J. Environ. Sci.

Institute of Environmental Studies and Research - Ain Shams University

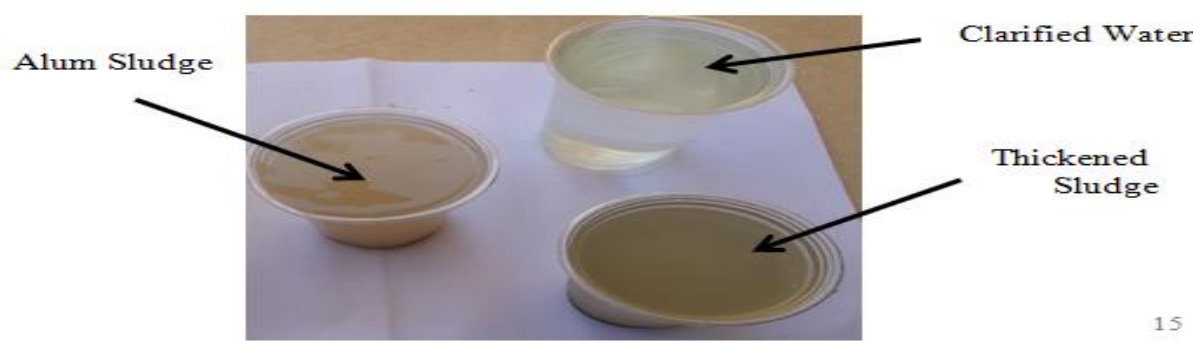

Figure (8): Convectional thickener sludge and water samples

Water analysis: The analyzed parameters shown in table (3) explain the difference between FMR and conventional thickener.

Table (3): comparison between pilot setup and conventional thickener.

\begin{tabular}{|c|c|c|c|c|c|}
\hline Parameters & Unit & \multicolumn{2}{|c|}{ FMR } & \multicolumn{2}{c|}{$\begin{array}{c}\text { Conventional } \\
\text { Thickener }\end{array}$} \\
\hline \hline ROF / SLR & $\mathrm{m} 3 / \mathrm{m} 2 / \mathrm{d}$ & 200 & 36 & 200 & 36 \\
\hline Alum Sludge Turbidity & $\mathrm{NTU}$ & 325 & 325 & 325 & 325 \\
\hline Alum Sludge TSS & $\mathrm{mg} / \mathrm{l}$ & 612 & 612 & 612 & 612 \\
\hline Filtered Water Turbidity & $\mathrm{NTU}$ & 28 & 8 & 105 & 76 \\
\hline Filtered Water TSS & $\mathrm{mg} / \mathrm{l}$ & 45 & 19 & 180 & 93 \\
\hline $\begin{array}{c}\text { Thickened Sludge } \\
\text { Turbidity }\end{array}$ & $\mathrm{NTU}$ & 827 & $>1000$ & 524 & 720 \\
\hline Thickened Sludge TSS & $\mathrm{mg} / \mathrm{l}$ & 2810 & 4540 & 1203 & 2760 \\
\hline
\end{tabular}

\section{CONCLUSION}

- Floatable media filter is a system based on the fundamental of the filtration processes.

- The optimum operating conditions for the proposed pilot setup are ranged between ROF 150 to $200 \mathrm{~m} 3 / \mathrm{m} 2 /$ day and media height between 500 to 600 $\mathrm{mm}$ to achieve filtered water turbidity less than $12 \mathrm{NTU}$. So it can feed the plant to increase its capacity. 
- The optimum ROW is equal to three times of ROF with interval time of 150 minutes of running at operating condition of ROF equal to 200 $\mathrm{m} 3 / \mathrm{m} 2 /$ day and media height is $500 \mathrm{~mm}$.

- Floatable media filter can be successfully applicable in thickening of alum sludge for the compact WTP.

- The efficiency of the FMR in thickening of alum sludge reaches to $30 \%$ while by using the conventional thickener reaches to $15 \%$ for the same sludge type.

\section{REFERENCES}

Andrew D. Eaton, Mary Ann H. Franson, American Public Health Association, (APHA 2005) Standard Methods for the Examination of Water \& Wastewater, 21st edition

Bache, D. H. and Gregory, R. (2010) Flocs and separation processes in drinking water treatment, IWA Publishing-AQUA | 59.1

Bache, D. H. (2003), Dewatering of aluminohumic sludge: impacts of hydroxide. Water Res. 37, $3289-3298$.

Bache, D. H. and Gregory, R. (2007), Flocs in Water Treatment. IWA Publishing, London

Bratby J. (2006), Coagulation and Flocculation in Water and wastewater Treatment. IWA Publishing, London, Seattle,pp,51.

El-Nahhas, K., (2011), Assessment of the drinking water clarification under condition of sludge return to flocculator, Fifteenth International Water Technology Conference.

Siriprapha Jangkorn, Sinchai Kuhakaew, Suwapee Theantanoo, (2011), Evaluation of reusing alum sludge, Journal of Environmental Sciences 23(4) 587-594

Statistics إدارة الإحصاء - قطاع الخدمات الفنية - الثركة القابضة لمياه الثرب بالقاهرة الكبرى Dept., Technical Service Sector (2011). 


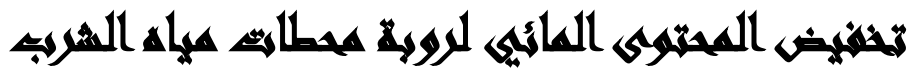

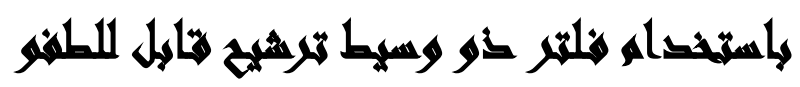

[

\author{
أحمد شفيق الجندي(')- طه عبد العظيم محمد عبد الرازق(')- شريف عبد المنعم

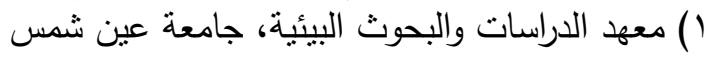

\section{المستخلصى}

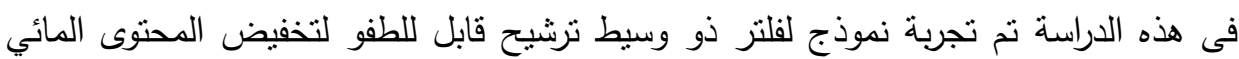

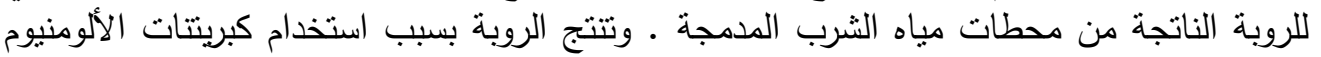

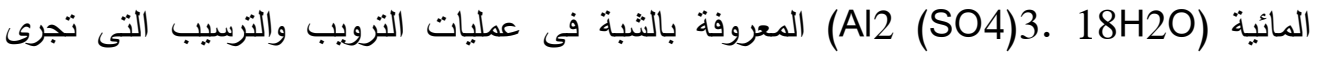

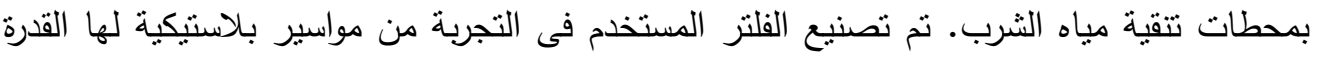

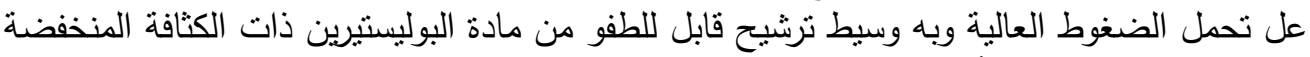

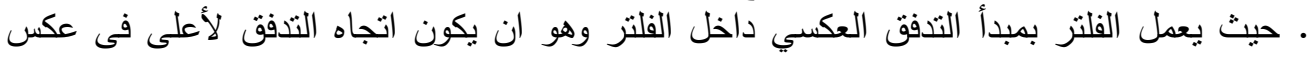

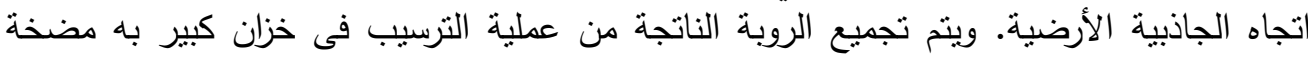

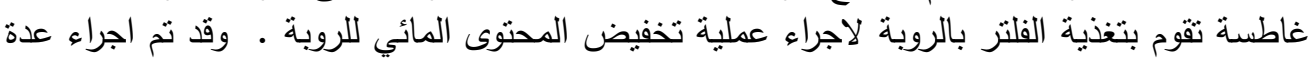

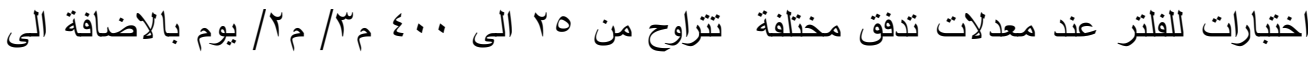

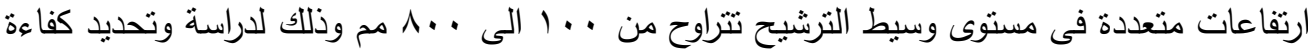

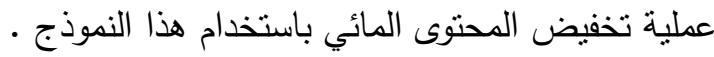

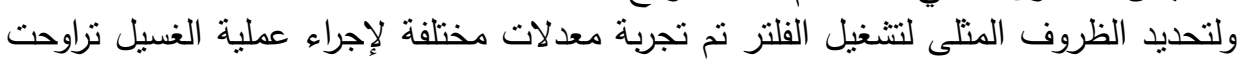

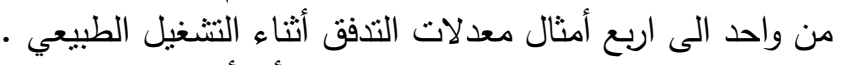

وبعد الانتهاء من هذه التجارب وجد أن أفضاء أفضل معدل تدفق أنثاء عملية التشغيل الطبيعي يتراوح

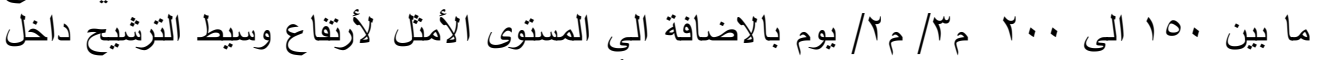

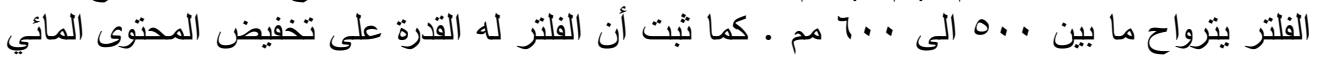

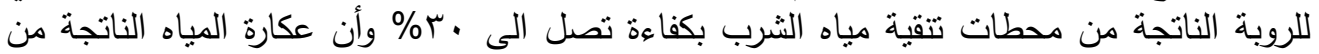

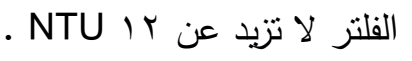

